Ciprofloxacin and Clostridium difficile--Associated Diarrhea •

Author(s): C. Thomas; C. L. Golledge; T. V. Riley

Reviewed work(s):

Source: Infection Control and Hospital Epidemiology, Vol. 23, No. 11 (November 2002), pp. 637-638

Published by: The University of Chicago Press on behalf of The Society for Healthcare Epidemiology of

America

Stable URL: http://www.jstor.org/stable/10.1086/503451

Accessed: 13/09/2012 11:09

Your use of the JSTOR archive indicates your acceptance of the Terms \& Conditions of Use, available at

http://www.jstor.org/page/info/about/policies/terms.jsp

JSTOR is a not-for-profit service that helps scholars, researchers, and students discover, use, and build upon a wide range of content in a trusted digital archive. We use information technology and tools to increase productivity and facilitate new forms of scholarship. For more information about JSTOR, please contact support@jstor.org. 
Letters to the Editor

\section{Ciprofloxacin and Clostridium difficile- Associated Diarrhea}

\section{To the Editor:}

We believe that the study reported by Yip et al. ${ }^{1}$ in the September 2001 issue of Infection Control and Hospital Epidemiology regarding exposure to ciprofloxacin as a risk factor for Clostridium difficile-associated diarrhea $(\mathrm{CDAD})$ is flawed from both an epidemiologic and a microbiological perspective.

Several issues regarding the research methodology and statistical analysis used in this study are worthy of comment. First, the authors matched controls to cases by date of admission, ward, age, and gender. They found that they could not also match on length of stay and had to use a second control group. If the authors intended to use logistic regression to analyze the results, then why did they match on so many factors? It would have been easier to match only on date of admission and ward, and then include the remaining variables in the analysis. This would have had the added advantage of exploring interaction effects (eg, between age and antibiotic exposure). Moreover, matching on date of admission in this study may not have been to any advantage because the study period was only 3 months. The local environment was not likely to have changed significantly during this period, and it would have been acceptable to randomly select controls from this period. Finally, matching on the factors described in this study does not control for comorbidities, as stated by the authors.

The authors concluded that ".. . patients with CDAD were at least five times more likely to have been exposed to ciprofloxacin than control patients. ..."The results should have been interpreted as patients with CDAD were between 1.2 and 24.8 times more likely to have been exposed to ciprofloxacin for the first control group, based on univariate analysis, and between 1.01 and 88.4 times for the second control group, based on multivariate analysis. These wide confidence intervals (CIs), although statistically significant, are of no real practical importance. Wide CIs reflect unstable odds ratio (OR) estimates that generally occur when the sample size is too small, reducing the power of the study. The lower bounds of CIs close to 1 (ie, the null value) provide evidence for lack of an effect.

When viewed in conjunction with other studies that have explored the association of ciprofloxacin with $C D A D$, this study adds nothing new. Shah et al. ${ }^{2}$ found a statistically significant association of ciprofloxacin exposure with $\mathrm{CDAD}$ using patients with diarrhea not due to $C$. difficile as controls. Although they did not report the OR and $\mathrm{CI}$, these could be calculated as 2.33 and 1.23 to 4.43 , respectively. Ciprofloxacin exposure remained significant in their multivariate analysis, along with macrolides, cefuroxime, and lactulose. Nath et al. ${ }^{3}$ also reported a statistically significant association . of ciprofloxacin in a multivariate model that also found clindamycin, ceftazidime, and cefuroxime to be independently associated with CDAD, but the CI of 1.05 to 13.79 provides little in terms of practical importance. Other studies have reported associations that have not been statistically significant. However, all had relatively small sample sizes and could have lacked power. ${ }^{4-8}$

Regarding the microbiology, Yip et al. ${ }^{1}$ state, "Ciprofloxacin and other oral quinolones are active against many intestinal bacteria. . .." This is true, but ciprofloxacin (unlike the newer fluoroquinolones) is not active against the anaerobic component of the intestinal flora and it is these bacteria that comprise the "colonization resistance barrier." 9 We previously demonstrated this in an in vitro model in which "treatment" with ciprofloxacin did not result in proliferation of $C$. difficile, whereas "treatment" with clindamycin, a known CDAD inciting agent, resulted in a significant increase in $C$. difficile. ${ }^{10}$ In addition, we investigated prospectively 213 patients receiving ciprofloxacin monotherapy and failed to show any association between CDAD and ciprofloxacin. ${ }^{10}$

Two of the references cited by Yip et al. in support of their argument ${ }^{11,12}$ were letters to the editor in Lancet in 1990. However, Yip et al. failed to mention our letter in Lancet in the same year ${ }^{13}$ that provides plausible explanations for the observations made by Bates et al. ${ }^{11}$ (prior Salmonella infection predisposing to C. difficile) and Cain and $0^{\prime} C^{\prime}{ }^{2}{ }^{12}$ (prior co-trimoxazole therapy).

The five patients described by McFarland et al., ${ }^{14}$ for whom ciprofloxacin was linked with $\mathrm{CDAD}$, all had serious disease, with four of the five having recurrences. That in itself suggests that factors other than ciprofloxacin may have been operating in most, if not all, of these cases.

Clinical data and our own continuing experience would suggest that the rate of ciprofloxacin-induced CDAD remains extremely low. Sir Charles Gairdner Hospital has been Australia's largest user of ciprofloxacin for more than 13 years (average expenditure, $\$ 220,000$ [Australian] per year), and we have not seen a case of ciprofloxacin-induced CDAD when ciprofloxacin has been used as monotherapy. Thus, we would argue that concern about $\mathrm{CDAD}$ following ciprofloxacin is not warranted. However, given the wider spectrum of activity of the newer fluoroquinolones, continued surveillance is justified.

\section{REFERENCES}

1. Yip C, Loeb M, Salama S, Moss L, Olde J. Quinolone use as a risk factor for nosocomial Clostridium difficile-associated diarrhea. Infect Control Hosp Epidemiol 2001;22:572575.

2. Shah S, Lewis A, Leopold D, Dunstan F, Woodhouse K. Gastric acid suppression does not promote clostridial diarrhoea in the eldery. $Q$ 2000:93:175-181.

3. Nath SK, Salama S, Persaud D, et al. Drug risk factors associated with a sustained outbreak of Clostridium difficile diarrhea in a teaching hospital. Can J Infect Dis 1994;5:270275

$\rightarrow$ 4. Hutin Y, Molina JM, Casin I, et al. Risk factors for Clostridium difficile-associated diarrhoea in HIV-infected patients. AIDS 1993;7:14411447.

$\rightarrow$ 5. Talon D, Bailly P, Delmee M, et al. Use of pulsed-fiek gel electrophoresis for investigation of an outbreak of Clostridium difficile infection among geriatric patients. Eur J Clin Microbiol Infect Dis 1995;14:987-993.

6. Watanakunakorn PW, Watanakunakorn C, Hazy J. Risk factors associated with Clostridium difficile diarrhea in hospitalized adult patients: a case-control study-sucralfate ingestion is not a negative risk factor. Infect Control Hosp Epidemiol 1996;17:232-235.

7. Halim HA, Peterson GM, Friesen WT, Ott AK. Case-controlled review of Clostridium difficileassociated diarrhoea in Southern Tasmania. $J$ Clin Pharm Ther 1997;22:391-397. 
8. Barbut F. Meynard JL, Guiguet M, et al. Clostridium difficile-associated diarrhea in HIV-infected patients: epidemiology and risk. factors. J AIDS 1997;16:176-181.

9. Reeves DS. The effect of quinolone antibacterials on the gastrointestinal flora compared with that of other antibacterials. J Antimicrob Chemother 1986;18:89-102.

10. Golledge CL, Carson CF, O'Neill GL, Bowman RA, Riley TV. Ciprofloxacin and Clostridium difficile-associated diarrhoea. $J$ Antimicrob Chemother 1992;30:141-147.

$\rightarrow$ 11. Bates CJ, Wilcox MH, Spencer RC, Harris DM. Ciprofloxacin and Clostridium difficile infection. Lancet 1990;336:1193.

12. Cain DB, O'Connor ME. Pseudomembranous colitis associated with ciprofloxacin. Lancet 1990;336:946.

13. Golledge CL, O'Neill GL, Carson CF, Bowman RA, Riley TV. Ciprofloxacin and pseudomembranous colitis. Lancet 1990;336: 1509-1510.

14. McFarland LV, Bawens JE, Melcher SA, Surawicz CM, Greenberg RN, Elmer GW. Ciprofloxacin-associated Clostridium difficile disease. Lancet 1995;346:977-978.

Claudia Thomas, BSc, PGDipHIthSci

Departments of Microbiology and Public Health

University of Western Australia Clayton L. Golledge, BSc(Med), MBBS

(Hons)

Division of Microbiology and Infectious Diseases

Western Australian Centre for Pathology and Medical Research

Thomas V. Riley, BAppsc, MAppEpid, PhD

Department of Microbiology University of Western Australia and

Division of Microbiology and Infectious Diseases

Western Australian Centre for Pathology and Medical Research

Nedlands, Perth, Western Australia

\section{The authors reply.}

We thank Thomas et al. for their interest in our study. We agree that matching only by date of admission and ward would have been a reasonable alternative approach. We disagree with their comments about matching on date of admission. Our decision to use date of admission was based on careful consideration of circumstances in our hospital, particularly staffing shortages. This variable can readily change during a 3 -month period, is potentially associated with nosocomial transmission, and, in our setting, is not easily measurable-all arguments for matching. Randomly selecting controls, as suggested by Thomas et al., may have led to a loss of precision compared with matching on length of stay. Regardless, the pertinent point is that we obtained similar results with relatively large effect sizes using two different sets of controls. In their interpretation of confidence intervals, Thomas et al. ignore the fact that it is the point estimate of the odds ratio that is most likely to reflect the "truth." The point estimates of the odds ratios for the two sets of controls, 5.5 and 6.7 , both based on multivariable analysis, obviously do not represent a "lack of effect" as suggested by Thomas et al. Their discussion about sample size and power is misinformed; these are a priori concepts that should not be used to interpret completed studies. ${ }^{1}$ Thomas et al. cite epidemiologic studies that in fact support our findings of an association between fluoroquinolone use and Clostridium difficile-associated diarrhea. ${ }^{2,3}$ We acknowledge that the generalizability of such studies may be limited. We would suggest that Thomas et al. exert similar caution when making generalizations based on their experience in a single hospital. We agree that continued surveillance of fluoroquinolones and Clostridium difficile-associated diarrhea is justified.

\section{REFERENCES}

1. Goodman SN, Berlin JA. The use of predicted confidence intervals when planning experiments and the misuse of power when interpreting results. Ann Intern Med 1994;121:200 206.

2. Shah S, Lewis A, Leopold D, Dunstan F, Woodhouse K Gastric acid suppression does not promote clostridial diarrhoea in the elderly. $Q M J 2000 ; 93: 175-181$.

3. Nath SK, Salama S, Persaud D, et al. Drug risk factors associated with a sustained outbreak of Clostridium difficile diarrhea in a teaching hospital. Can J Infect Dis 1994;5:270 275.

Mark Loeb, MD, MSc Departments of Pathology and Molecular Medicine and Clinical Epidemiology and Biostatistics McMaster University Hamilton, Ontario, Canada Clarwyn Yip, MD

Department of Medicine

Humber River Regional Hospital Toronto, Ontario, Canada

\section{Transmissions From \\ Infected Healthcare Providers to Patients Are Medical Errors}

\section{To the Editor:}

Do no harm. This is a principle all medical personnel live by and should be referred to whenever we discuss interactions between patients and healthcare providers. In the June issue of Infection Control and Hospital Epidemiology, there were two editorials, ${ }^{1,2}$ one article, ${ }^{3}$ and two letters ${ }^{4.5}$ regarding the transmission of hepatitis $B$ virus, hepatitis $C$ virus, and human immunodeficiency virus from surgical personnel to patients. It serves our collective interest to analyze this issue through the principle stated above and its necessary practical companion, reducing medical errors. After all, isn't transmission of disease in our healthcare institutions by definition a medical error?

A critical component of accident prevention is building systems that prevent errors from occurring. What we have learned from other industries, such as the aviation sector, is that rather than focusing on the individual, a successful strategy requires standardizing procedures that everyone in the system must follow. If an individual working inside the system has the choice of whether to follow an aspect of the recommended procedures, doesn't this in effect mean that there is no system? Instead, there is individual compliance or noncompliance. Could you imagine if the same "system" existed in the airline industry? Would we accept a situation in which the pilot could choose whether to conduct inspections before takeoff? Isn't a pilot with individual choice equivalent to a surgeon who can choose whether to be vaccinated or whether to be tested for hepatitis $B$ virus?

\section{REFERENCES}

$\rightarrow$ 1. Chiarello LA, Cardo DM. Preventing transmission of hepatitis B virus from surgeons to patients. Infect Control Hosp Epidemiol 2002; 23:301-302.

2. Paton S, Zou S, Giulivi A More should be done to protect surgical patients from interoperative hepatitis B infection. Infect Control Hosp Epidemiol 2002;23:303-305.

$\rightarrow$ 3. Spijkerman IJB, van Doorn L-J, Janssen $\mathrm{MHW}$, et al. Transmission of hepatitis $\mathrm{B}$ virus from a surgeon to his patients during highrisk and low-risk surgical procedures during 4 years. Infect Control Hosp Epidemiol 2002; $23: 306-312$

4. Fiser WP Jr. Should surgeons be tested for blood-borne pathogens? Infect Control Hosp Epidemiol 2002;23:296-297.

$\rightarrow$ 5. Ball RT Jr. Protecting patients from surgical hepatitis $\mathrm{C}$ virus infection. Infect Control Hosp Epidemiol 2002;23:297-298.

Bernadette Stringer, PhD, RN Department of Epidemiology and Biostatistics

The University of Western Ontario London, Ontario, Canada 